\section{Papeles de POBLACIÓN}

Accinelli, Elvio; Brida, Juan Gabriel; Sánchez Carrera, Edgar J.; Punzo, Lionello F. Emergence of long run behaviours in a game theoretic setting with host and guest populations: residents and tourists

Papeles de Población, vol. 14, núm. 58, octubre-diciembre, 2008, pp. 23-39

Universidad Autónoma del Estado de México

Toluca, México 


\title{
Emergence of long run behaviours in a game theoretic setting with host and guest populations: residents and tourists
}

\author{
Elvio ACCINELLI, Juan Gabriel BRIDA, \\ Edgar J. SÁNCHEZ CARRERA y Lionello F. PUNZO \\ Universidad Autónoma de San Luis Potosí/Free University of Bolzano, Italy/ \\ Facoltà d'Economia Richard M. Goodwin, Italy/University of Siena
}

Abstract

In this paper we model tourism in the framework of multi-population dynamics and analyze the time pattern of its development through the evolving interaction between two populations feeding on a common space-resource. Each population might be structured in two (or more) "clubs" of members sharing social and economic interests as to the management of the relevant resource. Such situation will be modeled by a version of the well known replicator dynamics. The strategies are characterized as environmentalist and not environmentalist behaviors of residents and tourist. We show that the properties of an environmentalist behavior as stable strategy, Nash equilibrium and dynamic replicator solution. JEL classification: C72; C73; D74; L83.

Key words: tourism sustainability, structured populations, replicator dynamics.
Resumen

Emergencia de comportamientos de largo plazo en un ambiente de juego teórico con poblaciones locales e invitadas: residentes y turistas

En este trabajo modelamos el turismo en el marco de la dinámica multipoblacional y analizamos el patrón de tiempo de su desarrollo a través de la interacción evolutiva entre dos poblaciones que se sustentan de un espacio-recurso común. Cada población puede estar estructurada en dos (o más) "clubes" de miembros que comparten intereses económicos y sociales como el manejo del recurso relevante. Tal situación se modelará con una versión del conocido dinámica del replicador. Las estrategias se caracterizan como ambientalistas y no-ambientalistas de los residentes y turistas. Mostramos que las propiedades de un comportamiento ambientalista como solución de estrategia estable, equilibrio de Nash y dinámica del repricador. Clasificaciones JEL: C72, C73, D75; L83.

Palabras clave: sostenibilidad turística, poblaciones estructuradas, replicador de dinámicas.

\section{Introduction. Tourism development: the other side of the story}

I $\mathrm{n}$ this paper, tourism is modeled within a multi-population framework and the time pattern of its impact is analyzed as the evolution of the interaction between two structured populations feeding over the same set

of resources. Of course, being the biological similarity that allows the use of the metaphor, individuals are assumed to be homo economicus, and therefore they (are depicted) act rationally. Further, each population will in general be structured in two (in reality can be more) "communities" or "clubs" (the two words will 
be used interchangeably) a community being a group of members of a given population sharing certain social and economic interests as to the management of the relevant resources. Thus, each club has in principle a distinct set of strategies and resources share some of the characteristics of the so called commons. The peculiarity is that while they were commons for the residents up to a point in the history of the host population, the extension of access with the implied use privileges is forcefully demanded by the newly arrived tourists. This sets in an interaction between populations through the choice they are making over exploitation.

To simplify we assign a single strategy to identify a given club. Furthermore, strategies are symmetric in the sense that a unique set with two strategies only is available to both populations. They will be called sustainability and nonsustainability of the environment. ${ }^{1}$ That is to say, one strategy may be characterized as conservative and its opposite as depredative of local resources. ${ }^{2}$

In the middle between the two outcomes, a variety of interaction schemes can lead to stable/unstable, or metastable equilibria to transient states on paths towards some equilibrium elsewhere, as the result of clubs playing different strategies. This has a dynamic of an evolutionary nature. To represent such a peculiar situation, we use Evolutionary Game Theory; in particular, it is applied in the theory of evolution of interacting structured populations. Interaction between the strategies and corresponding player clubs gives rise to a rich dynamics; outcomes has inherently unstable, as is known, others evolutionary stable. The history of such outcomes will be tracked down through the evolution of the relative sizes of the two formatted clubs on their populations, and of their associated strategies. Such approach lends itself to be odeled by a version of the well known replicator dynamics. In fact, shifting across strategies and therefore club memberships of individuals of a given population will be viewed as the result of an imitation mechanism and/or the adoption of a better option.

This paper is organized as follows. Next section gives a motivation, grounded on the variety of empirical experiences of tourism development and community relations. This is an alternative to the conventional life cycle interpretation. The following section lays out the community structure of the population whose dynamics is analyzed under two distinct hypotheses in Sections 3 and 4. It turns out that they both lead to a version of the well known replicator dynamics, still they account tentatively for a certain number of behaviors and for their often undesired outcomes. Final comments conclude the exercise.

\footnotetext{
${ }^{1}$ See Pan (2006) as one of the few examples of applied game theory in tourism.

${ }^{2}$ Because cooperation among them about a sustainable management can emerge, but cooperation about a non-sustainable or speculative tapping of such commons can be an alternative outcome, we do not use the conventional terminology of cooperative and no cooperative strategy.
} 
Emergence of long run bahaviours in a game theoretic setting.../E. ACCINELLL et al.

\section{Motivation}

That destinations (and related tourist products) do have a history is well known since the introduction of the so called life cycle theory. A history implies that they are bound to change over time qualitatively (and for many of their measurable characteristics, also quantitatively) as an effect of the tourist flows and policy, at the same time as changing in their market positions. This way, however, time evolution is recounted from the point of view of the tourist industry and the tourist only: as the very name says, a destination is dedicated to someone's use (the tourist's of course), getting there and enjoying its many attractions with the necessarily related services to do so is the job of a generally specialized production structure. It is the physical, cultural and economic support of some tourist product, in totality or only partially. In this paper, we adhere to an alternative view: destinations are (almost always) someone's home. From the seminal work [Smith, 1989], this point of view is well radicated in other fields of tourism studies but in economics and management, are dominated by a demand driven approach that has a Keynesian view to tourist's demand and a management approach to the supply of tourist services. The social-economic conditions of the production of these latter are left out of the analysis, as if they were the exclusive domain of other disciplines.

Treating destinations as somebody's home is one of the ways to bring in those conditions. A destination is where two populations meet: the residents encounter the alien, the guest, the foreigner. A tourist is one such foreigner, distinguished from other types for her motivation and other well known conditions as to the length of stay, source of finance, etc. The large experience of Local Agenda 21 for tourism accumulated in e.g. Europe recently, has brought to the foreground the importance of this viewpoint, as it highlights the key problem: how the two populations come to terms with the problems of living together, which becomes economically the problem of how to share flows of services from resources existing at the destination. And the immediate issue is how to share the responsibility of maintaining such resources in a sustainable manner, i.e. with a look at their long run stock levels while tapping as many current benefits as possible. The issue of sustainable tourism is key in this framework. The histories of many destinations can be told in a light that is complementary to the life cycle's theory, as the varied evolution of such complex relation between tourists and residents mediated by the local resources.

There is a variety on the world market, readily available for our analysis, and repeating qualitative patterns can be recognized. Some have evolved from villages and/or towns into the tourism monocultures they are at the present, where tourism

is the unique resource value converting activity and residents only work in this trade; some are on the way though at different speeds; some have stopped short 
of this end for different reasons, some exogenous some policy decisions, and may be in need of some strategic re-thinking. Some have retrieved a residents' only situation having exited from the tourist market and returned to a situation that only looks like the original one in that geographical coordinates are unchanged. ${ }^{3}$

Behind these topical situations there are characteristic schemes of interaction between the two populations varying in absolute and relative sizes and in composition, and a varied portfolio of evolutive patterns in time, some involving high some low equilibria, some stable some unstable. We can thus rationalize the exemplary histories before us, but also predict the likely evolution of scenarios that are proving still on the move, and finally derive some prescription of tourism development policy.

We can specify a given form of interaction as the outcome of the matching of two strategies (a strategy being an intentional decision of acting in a certain manner), the latter can be specified according to two basic models. Population dynamics in biology is therefore where we have to start from for this type of study.

If we take the point of view of Local Agenda 21, sustainable management of local broadly defined resources is the objective of the interaction, and therefore we can introduce the choice of sustainability or no sustainability of the environment as two alternative strategies that can be played by residents and tourists alike, and see the various alternative outcomes. ${ }^{4}$ Hence, the strategy can be specified as one of sharing or not sharing such resource, the former being the situation where an environmentalist behavior is proposed, and social integration and peaceful living together may emerge, the latter implying partial or total separation of the two populations whose habits do not merge and they live apart one from another. The latter viewpoint carries us directly to the analysis of Tourist Carrying Capacity (TCC). ${ }^{5}$ While the two approaches and hybrid forms of them are complementary, in this paper the former will generally be emphasized, with occasional references to interpretations based upon the latter.

\section{Resident and tourist populations}

The histories referred to in the previous section all have a bearing with the basic issue of sustainable tourism: they can be interpreted as various solutions (some good some bad, some we do not know yet) to this issue.

\footnotetext{
${ }^{3}$ A good description of the residents' attitudes towards tourism can be found in Harrill (2004), Hernandez et al. (1996) Kathleen et al. (2000), Pennington (2005) and Zhang et al. (2006).

${ }^{4}$ As Bimonte and Punzo (2006) pointed out, the notion of metaphor can be introduced of a single space resource as the container of all natural and manmade resources of a given destination.

${ }^{5}$ See Casagrandi and Rinaldi (2002), Bimonte and Punzo (2006) for definitions of tourism carrying capacity of a region. In Rambonilaza (2006), carrying capacity is used to determine prices of tourist destinations.
} 
Emergence of long run bahaviours in a game theoretic setting.../E. ACCINELLI et al.

Tourism sustainability (TS) is an issue with many facets, but surely the necessary condition for its realization is the sustainable management of natural and man-made resources at the given territory. The foregoing game setting will be defined accordingly. TS will appear as the property possibly associated with one such equilibrium outcome (see Bimonte and Punzo, 2006).

Let us assume that current people, in a given tourist region, can be distinguished into two populations, residents $R$ and tourists $T$. On the issue of sustainable tourism, within each population we have the club of those environmentalists and the club of not, respectively $E$ and $N E$.

In each period of time an individual of one population, ${ }^{6} h$, playing $i \in\{E, N E\}$, is an $i$-th strategist. Anyway, people behavior can change over time because they have memory and then, they ask about their past experiences, with probability $r_{i}^{h}$, whether they were doing a right behavior. Let $p_{i j}^{h}$ be the probability to change from the $i$-th to the $j$-th strategy. Clearly, $r_{i}^{h} p_{j}^{h}$ is the probability of moving from one club to the other one. Let $\mathrm{e}_{\mathrm{E}}=(1,0)$ and $\mathrm{e}_{\mathrm{NE}}=(0,1)$ indicate the vectors of pure strategies, $E$ or $N E$, independently from the population, $h$, of residents and tourists.

Let now assume that the probability to change strategy is a function of the proportion of members of the club she belongs to. We think of a tourist who is considering whether to change or not her strategy, taking into account the behaviors of the other fellows she is meeting and will totally ignore the residents' decisions. Let it be the same for residents' decisions. Thus the expected change in the share of players type $I$ in the population $h$ they belong to, will be given on average by the probability of a $j$ - club member of moving into the i-th club multiplied by the existing share of members in his initial club less the probability of members of the $i$-th to move over to the $j$-th club weighted in the same way. For a given population $h$ this hypothesis yields the following equation of motion

$$
\begin{gathered}
\dot{x}_{i}^{h}=r_{j}^{h} p_{j i}^{h} x_{j}^{h}-r_{i}^{h} p_{i j}^{h} x_{i}^{h}, \\
\forall j \neq i, i \text { and } j \in\{E, N E\} \text { and } h \in\{R, T\} .
\end{gathered}
$$

\section{Keeping up with the johns}

Think of an individual's decision as to whether stick to a strategy/club or change over, a function of the type of individuals of her own population she encounters. This simplistic hypothesis still captures certain behaviours and consequences

${ }^{6}$ Let $\mathrm{x}^{\tau} \in \mathrm{R}^{2}$ be the space of strategies, such that $\mathrm{x}^{\mathrm{P}}=\left(\mathrm{x}^{\mathrm{P}}{ }_{C}, \mathrm{x}^{\mathrm{P}}{ }_{\mathrm{NC}}\right) \mathrm{P} \in\{\mathrm{R}, \mathrm{T}\}$ is normalized to $\mathrm{x}_{\mathrm{C}}^{\tau}+\mathrm{x}_{\mathrm{NC}}^{\tau}=1$ and each entry is the share of individuals in the respective club over the total population. 
thereof, to be encountered in e.g. tourist enclaves and or in package tours, whereby tourist behaviours is self-enforcing and often brings about the diffusion and the domination of tourists' own cultural characters. ${ }^{7}$ Sometimes, bad behaviours from being initially confined to some members of a population through imitation can spread an even become dominant: sexual tourism, vandalism and hooliganism being well known cases that can be thought to fall within this interpretation. Examples for the residents can similarly be found, where sustainability or not of the environment, can emerge as a result of the principle "do what your neighbor do".

Thus,

(i) let us assume that the decision of an individual depends upon the utility deriving from it

$$
u^{h}\left(e_{i}, x^{-h}\right),
$$

where $-\mathrm{h} \epsilon\{\mathrm{R}, \mathrm{T}\}$ means that $h$ population is facing the opposite one, and the share of individuals in her same club:

$$
r_{i}^{h}=f_{i}^{h}\left(\mathrm{E}\left[u^{h}\left(e_{i}, x^{-h}\right)\right]\right)
$$

Function $f_{i}^{\tau}()$ is reasonably interpreted as the propensity of a member of the $i$-th club to considers switching membership as a function of the expected utility gains from such a choice.

(ii) next let us assume that once opted for a change, she will adopt the strategy chosen by her neighbor, i. e.,

$$
p(i \rightarrow j / \text { she consider to change strategy })=p_{i j}^{h}=x_{j}^{h} \quad \forall i, j \in\{E, N E\}
$$

For (1) these assumptions yield the system of equations

$$
\dot{x}_{i}^{h}=x_{j}^{h} f_{j}^{h}\left(u^{h}\left(e_{j}, x^{-h}\right)\right) x_{i}^{h}-x_{i}^{h} f_{i}^{h}\left(u^{h}\left(e_{i}, x^{-h}\right)\right) x_{j}^{h}
$$

or equivalently,

$$
\dot{x}_{i}^{h}=\left(1-x_{i}^{h}\right) x_{i}^{h}\left[f_{j}^{h}\left(u^{h}\left(e_{j}, x^{-h}\right)\right)-f_{i}^{h}\left(u^{h}\left(e_{i}, x^{-h}\right)\right)\right]
$$

This is the general form of a dynamical system representing the evolution of a two-population/four club structure of tourists and residents. It is a system of four simultaneous equations in four state variables (a state variable being the share of

\footnotetext{
${ }^{7}$ Typical of the nationality enclaves around the world, the tourist resort type of behaviour implicitly emphasizing the asymmetric relation with local population, the separateness of the tourist from the context, finally the nowhere character of many such retreats.
} 
Emergence of long run bahaviours in a game theoretic setting.../E. ACCINELLI et al.

the club members over their respective population). Because the normalization, $x_{E}^{h}+x_{E}^{h}=1$, (3) can be reduced to two equations in two independent state variables. Taking advantage of this property, from now onwards we choose variables $x_{E}^{R}$ and $x_{E}^{T}$ with their respective equations.

For a first grasp of the problem, let $f_{i}^{h}$ be population specific through the same across all its components independently from club membership, and furthermore to be linear in the utility levels. Thus, it makes sense to think that the propensity to switch behaviour will be decreasing in the level of the expected utility

$$
f_{i}^{\tau}\left(\mathrm{E}\left[u^{h}\left(e_{i}, x^{-h}\right)\right)\right)=\alpha^{h}-\beta^{h} u^{h}\left(e_{i}, x^{-h}\right)
$$

with $\alpha^{h}, \beta^{h} \geq 0$. To get a full linear form we consider that

$$
u^{h}\left(e_{i}, x^{-h}\right)=e_{i} A^{h} x^{-h}
$$

in other words, that utility is a linear function of both variables, through a populationspecific matrix of weights or constant coefficients, $A^{h} \in \mathrm{M}_{2 \times 2},(h \in\{R, T\})$. This latter assumption implies that utility levels reflect population specific properties, i.e., broadly speaking preference structures over their outcomes. This reduces the previous model to a more simplified version:

$$
\left.\dot{x}_{E}^{h}=\beta^{h} x_{E}^{h}\left(1-x_{E}^{h}\right)(1,-1) A^{h} x_{E}^{-h}\right], \quad \forall h \in\{R, T\}
$$

or equivalently,

$$
\left\{\begin{array}{l}
\dot{x}_{E}^{R}=\beta^{R} x_{E}^{R}\left(1-x_{E}^{R}\right)\left(m^{R} x_{E}^{T}+n^{R}\right) \\
\dot{x}_{E}^{T}=\beta^{T} x_{E}^{T}\left(1-x_{E}^{T}\right)\left(m^{T} x_{E}^{R}+n^{T}\right)
\end{array}\right.
$$

whose coefficients $m^{\mathrm{T}}$ and $n^{\mathrm{T}}$ depend upon the entries of the two populationspecific matrices $A^{\mathrm{T}}$ and $A^{\mathrm{R}}$.

\section{Dynamic stability and Nash properties}

System (5) admits five stationary states, i.e., $(0,0) ;(0,1) ;(1,0) ;(1,1)$ and a positive interior equilibrium

$$
\bar{P}=\left(\bar{x}_{E}^{R}, \bar{x}_{E}^{T}\right) \text { where }
$$

$$
\bar{x}_{E}^{R}=-\frac{n^{R}}{m^{R}} ; \quad \bar{x}_{E}^{T}=-\frac{n^{T}}{m^{T}}
$$


The interesting case is when we have $\bar{P}$ as an interior equilibrium of the square $\mathrm{C}=[0,1] \times[0,1]$ and this holds when

$$
0<-\frac{n^{R}}{m^{R}}<1 \text { and } 0<-\frac{n^{T}}{m^{T}}<1
$$

while the other four equilibria are the corners of the square itself. We can proceed to inquire about the stability of the five equilibria.

Recall that the two structured populations have to decide whether to share (in part or totally) the space resource of one of them, clearly the trivial equilibrium is one where none of the residents is inclined to admit tourists, nor tourists are willing to mix up with residents: all the territory for them or they walk away, unless they can enforce their wish through coercion and expulsion. ${ }^{8}$

On the other hand, there is an equilibrium at the opposite corner (where a partitioned club involve all of its respective population), this is the case where reciprocal integration of the two populations is complete as they find a way to share the existing limited resources. This is where the population structure supporting any feasible path of sustainable tourism development can be located, the previously called necessary condition for TS. This may take up many different shapes and be realized in a variety of ways: sustainable tourism has no unique recipe but the tourist and resident populations can find their own, at least in principle, reflecting beneficial conditions. The two remaining border equilibria show a different club dominating the two populations and in a sense a mismatch between strategies. It is likely that these two situations cannot establish themselves for long [Bimonte S., L. F. and Punzo (2006)], or in other words that unstable, but to assess this we need to address the stability issue. Finally, the interior equilibrium will be seen to be the most difficult to make sense of. Stability analysis looks at the properties of the Jacobean of the system (5)

$$
J\left(x_{E}^{R}, x_{E}^{T}\right)=\left|\begin{array}{cc}
\beta^{R}\left(1-2 x_{E}^{T}\right)\left(m^{T} x_{E}^{R}+n^{T}\right) & \beta^{R} m^{T} x_{E}^{T}\left(1-x_{E}^{T}\right) \\
\beta^{T} m^{R} x_{E}^{R}\left(1-x_{E}^{R}\right) & \beta^{T}\left(1-2 x_{E}^{R}\right)\left(m^{R} x_{E}^{T}+n^{R}\right)
\end{array}\right|
$$

whose value is, of course, dependent of the population specific matrices, among other things. The following picture depicts the five equilibria, including an interior one, with the structure when $P$ is unstable.

\footnotetext{
${ }^{8}$ Think of the land expropriation to build up resorts in certain parts of the least developed countries. The case where residents have the upper hand is rarer, but perhaps the villages of Chiapas that communities have decided to close to the tourist, can be one such rare example.
} 
Emergence of long run bahaviours in a game theoretic setting.../E. ACCINELLI et al.

FIGURE 1

THE TOURISM DEVELOPMENT SCENARIOS: THE EQUILIBRIA

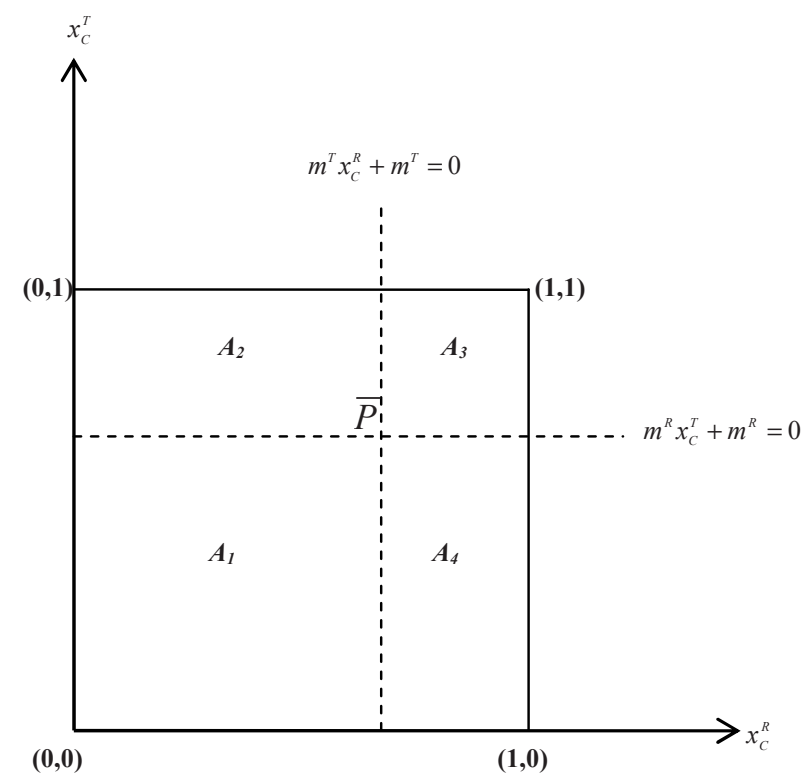

Thus,

- If $n^{R}<0$ and $n^{T}<0$, the interior equilibrium $\bar{P}$ is the unique attractor in $C$.

- If $n^{R}>0$ and $n^{T}>0$, on the contrary, $\bar{P}$ is the unique repulsor, all other four being local attractors in $C$. The latter in partitioned in four regions, the respective basins of attractions of the corner attractors.

- Otherwise, $\bar{P}$ is a saddle point, with the outset going through $C$ from south west to north east, or the contrary. Accordingly the corner equilibria may be attractors or repulsors: in the former case $(0,0)$ and $(1,1)$ will turn up to be repulsors and $(1,0)$ and $(0,1)$ attractors; the opposite in the latter case.

Recall that matrices $A^{T}$ and $A^{R}$ are the payoff matrices of a bi-matrix game with two players, the population of tourists $T$ and the population $R$ of residents. Corner equilibria correspond to the populations playing both pure strategies; an interior equilibrium corresponds to mixed strategies, weights being the share of a community on the total of its own population. The advantage of this interpretation is basically in that TS becomes automatically associated as a property to the unique equilibrium where both populations homogeneously play sustainability in the management of the local resources, or the corner equilibrium $(1,1)$. The 
alternative is the $(0,0)$ equilibrium where both playing non sustainability means that they have depredative behaviors. At the other two corner equilibria, mixed populations emerge and interact on both sides of the encounter. Whether this situation can be stable, is a delicate one. It surely can be as long as cross population alliances (and imitation, as well) are excluded (and of course provided the previously stated mathematical conditions be satisfied). Such quite inconvenient possibility of cross population interdependence will be excluded hereafter, and briefly commented upon in the conclusions.

Given the game theoretic setting, the analysis of the relation between dynamical equilibria and Nash equilibria provides useful additional information. The following properties can be easily derived (see Weibull, 1995):

- Stability is a sufficient condition for a dynamic equilibrium to be a Nash equilibrium or the players do not have incentives to change their behavior.

- Being an interior point is sufficient for an equilibrium to be a Nash equilibrium.

Therefore, $n^{R}<0$ and $n^{T}<0$, at the interior equilibrium $\bar{P}$ agents have no incentives to switch away from the chosen strategy, moreover if they happen to be shocked away from it, they will return. Thus, the relative sizes of $E$ and $N E$ communities within either population will be evolutionary stable.

On the contrary, i.e. when $n^{R}>0$ and $n^{T}>0$, the repulsor $\bar{P}$ is such that any slight shock or move away from it, will initialize a path systematically diverging towards one of the corner equilibria where we have homogeneous, or single community, populations.

These combined properties lend themselves to interpret some of the tourism development scenarios we know of. First of all, it shows how fragile can be the environmentalist equilibrium associated with tourism sustainability: stability (depending upon the coefficients of the payoff matrices) is to be hoped for to ensure that once established cooperation be implemented forever, which is the condition of material realization of the path associated with TS, once agreed upon. TS equilibrium may exist and be practically unreachable. This forcefully indicates that TS has to become a policy target, rather than to be expected as the natural outcome of population interaction.

\section{Picking up the most successful strategy}

Now a tourist or a resident consider changing strategy imitating the most successful strategy played by members of the same population. The rule states to choose the actions with the best results, with a probability proportional to the expected gains. In other words, a tourist (a resident, respectively) will change over to a different strategy played by another member of her population if and 
Emergence of long run bahaviours in a game theoretic setting.../E. ACCINELLL et al.

only if the latter brings a greater benefit in terms of expected utility. In this case, for the TS equilibrium $(1,1)$ to be established through interaction, the cooperative strategy has to be expected to have higher returns to each population, so that only cooperative communities will survive and interact. Again we have an indication for tourism policy when this is not the case: altering the terms of the alternative returns.

Let us assume an individual of population $h \in\{R, T\}$ in the club $j$ meets somebody of the alternative club, $i$, and that the former will change over to the latter membership/strategy if

$$
u^{h}\left(e_{i}, x^{-h}\right)>u^{h}\left(e_{j}, x^{-h}\right), \quad \forall i \neq j \in\{E, N E\}
$$

Hence the utility of each individual depends on her own strategy and on the characteristics of the individuals of the other population. Further, we assume that there is some uncertainty in the estimated return of the alternative strategies, so that must estimate the value $u^{h}\left(e_{i}, x^{-h}\right)$. Thus, the probability of a $j$-strategist to change her behavior is given by the probability of encountering an $i$-strategist multiplied by the probability that the estimator of the return

$$
\bar{D}=\mathrm{u}^{\mathrm{h}}\left(\mathrm{e}_{\mathrm{i}}, \mathrm{x}^{-\mathrm{h}}\right)-\mathrm{u}^{\mathrm{h}}\left(\mathrm{e}_{\mathrm{j}}, \mathrm{x}^{-\mathrm{h}}\right) \text { is positive. }
$$

Then, her probability $p_{j i}^{h}$ to change from the $j$-th to the $i$-th club/strategy will be $x_{i}$ times $\mathrm{P}^{\mathrm{h}}(\bar{D} \geq 0)$, the probability of her observing

$$
\begin{aligned}
\bar{D} & =\mathrm{u}^{\mathrm{h}}\left(\mathrm{e}_{\mathrm{i}}, \mathrm{x}^{-\mathrm{h}}\right)-\mathrm{u}^{\mathrm{h}}\left(\mathrm{e}_{\mathrm{j}}, \mathrm{x}^{-\mathrm{h}}\right)>0 .{ }^{9} \text { Therefore, } \\
p_{i j}^{h} & =x_{j i}^{h} P^{h}(\bar{D} \geq 0)
\end{aligned}
$$

Let us assume that depends upon the true value of the difference $\mathrm{u}^{\mathrm{h}}\left(\mathrm{e}_{\mathrm{i}}, \mathrm{x}^{-\mathrm{h}}\right)-\mathrm{u}^{\mathrm{h}}\left(\mathrm{e}_{\mathrm{j}}, \mathrm{x}^{-\mathrm{h}}\right)$ which is unknown to the $i$-th strategist. That is to say,

$$
P^{h}(\bar{D} \geq 0)=\phi^{h}\left(u^{h}\left(e_{j}, x^{-h}\right)-u^{h}\left(e_{i}, x^{-h}\right)\right)
$$

Therefore the probability of a $j$-th strategist in the population $h$ to observe a positive $\bar{D}$ value, increases with the true value of the difference $\mathrm{u}^{\mathrm{h}}\left(\mathrm{e}_{\mathrm{j}}, \mathrm{x}^{-\mathrm{h}}\right)-\mathrm{u}^{\mathrm{h}}\left(\mathrm{e}_{\mathrm{i}}, \mathrm{x}^{-\mathrm{h}}\right)$. To simplify, let $\mathrm{u}^{\mathrm{h}}\left(\mathrm{e}_{\mathrm{i}}, \mathrm{x}^{-\mathrm{h}}\right)$ be linear, i.e.,

$$
u^{h}\left(e_{i}, x^{-h}\right)=e_{i} A^{h} x^{h}
$$

${ }^{9}$ I.e. the probability of the event where the estimator of the utility associated to the $i$-th club/strategy, given the characteristics of the other population, be greater than her own strategy given the characteristics of the other population. 
Thus the probability of a $j$-th strategist to become an $i$-th one is given by,

$$
p_{j i}^{h}\left(u^{h}\left(e_{i}-e_{j}, x^{h}\right)\right)=\phi^{h}\left(u^{h}\left(e_{i}-e_{j}, x^{-h}\right)\right) x_{i}^{h}
$$

Hence, a new equation of motion for the $i$-strategist of the $h$ population is given by,

$$
\dot{x}_{i}^{h}=\left\lfloor x_{j}^{h} p_{j i}^{h}-p_{i j}^{h} x_{i}^{h}\right\rfloor x_{i}^{h}, \quad \forall i \neq j \in\{E, N E\}
$$

In our case the equation can be written as,

$$
\left.\dot{x}_{i}^{h}=x_{j}^{h} x_{i}^{h} \mid \phi^{h}\left(u^{h}\left(e_{j}-e_{i}, x^{-h}\right)\right)-\phi^{h}\left(u^{h}\left(e_{i}-e_{j}, x^{-h}\right)\right)\right\rfloor
$$

a first order approximation is,

$$
\dot{x}_{i}^{h}=x_{j}^{h} \phi^{h^{\prime}}\left(0, x^{h}\right)\left[u^{h}\left(e_{j}-e_{i}, x^{-h}\right)-u^{h}\left(e_{j}-e_{i}, x^{-h}\right)\right]=2 \phi^{h^{\prime}}\left(0, x^{h}\right) u^{h}\left(e_{i}-x^{h}, x^{-h}\right) x_{i}^{h}
$$

Moreover, in a neighborhood of an interior stationary point, the dynamics can be represented by a replicator dynamics. When the equilibrium is non hyperbolic the stability analysis on local type can be analyzed using the linear part of the nonlinear system.

In the special case where $\phi^{h}$ is linear;

$$
\phi^{h}=\lambda^{h}+\mu^{h} u^{h}\left(e_{j}-e_{i}, x^{h}\right)
$$

with $\lambda^{h}$ and $\mu^{h}$

$$
0 \leq \lambda^{h}+\mu^{h} u\left(x^{h}, x^{-h}\right) \leq 1, \quad x \in\left\{z \in R_{+}^{2}: \max _{i=1,2} z_{i} \leq 1\right\}
$$

we get the equation

$$
\dot{x}_{i}^{h}=2 \mu^{h} u^{h}\left(e_{i}-x^{h}, x^{-h}\right) x_{i}^{h}
$$

In this case, stability analysis is similar to the simple imitation model. Although the model is different from the one of simple imitation, as long as the linear approximation is mathematically valid, it permits to obtain an evolutionary dynamics of the same type. Hence, similar conclusions can be applied to the issue of the relation between stability and Nash equilibrium.

The real justification, for this new modeling extension, describes an observed behavior. Because people behave under rational expectations are choosing an 
Emergence of long run bahaviours in a game theoretic setting.../E. ACCINELLI et al.

expected maximization of their benefits, while in the former they behaved in a way of do what the others do. The next propositions summarize our main results:

Proposition 1. A rational behavior depends on individual expected payoffs facing opposite strategists. The evolution of this behavior is represented by a replicator dynamic solution and it depends on the initial conditions, i.e., the initial distribution of the population types.

Consequently, with the above proposition the mutations appear as an exogenous factor that can modify the evolution of the future behavior of the individuals. How long this modification is, depends on the stability of the equilibrium solution for this dynamical system.

Proposition 2. A rational behavior depends on the initial conditions, i.e., a rational behavior can be one or the other, environmentalist or not.

Therefore, as for the present case one can point out how often even undesirable behaviors are observed on the part of individuals expecting private gains out of them, that is to say, not taking into account any social benefit that may derive from a sustainable management of resources.

Over harvesting of them, by the tourists like by the residents, is often linked with such an effect of a short sighted rational action. To change such a situation, and for instance induce in such case an environmentally minded attitude and action on the part of both populations, we have to alter the structure of the (expected) gains, or influence expectations, or finally force or educate to a more far sighted and mindful attitude towards local resources. If this proves difficult with residents facing stringencies in the short run and thus looking for their immediate alleviation, more difficult will surely be to influence through purely economic or legal instruments such attitudes onto tourists. Its relationship with the territory and its resources is by definition and in the majority of case too short to elicit such a care. This is the challenge of TS.

\section{By way of conclusion}

Although the previous models embed the same type of replicator dynamics, the novelty there is that communities within the same population need not converge to the same strategy, i.e. merging into a strategically homogeneous population. This opens the door to the description of the latent and sometime explicit reasons of clash and conflict among communities within a population: e.g., between those who gain and those who do not gain from tourism, on the part of the host population. This can equally be between community of responsible tourists, or else tourist that having invested in repeated relations through frequent returns to the territory, have naturally a longer run perspective about its integrity, and short term, occasional tourists. While these different systems of valuations of benefits is behind our simplified story of the two strategies and their supporting 
communities or clubs, still the present analysis is also here (like at other points, some seen in the text above) much too simplified.

A full modeling effort is to be tackled; the reality gives us a variety of experiences as the natural background for policy oriented considerations. Such full modeling will probably call for more sophisticated, but also different in nature, and probably more computational than classical mathematical techniques. This is very much in the spirit and in the practice of most evolutionary analysis, whether within or without the game theoretic setting.

As the anthropologists are very well aware of, economic and social contacts among heterogeneous communities may and often do set in mechanisms of convergence in habits and cultural cross-fertilizations, positive and negative. We have modeled this in our framework, though excluding the case of cross interdependence. This was, which indeed plays an important role in explaining many observed paths of tourist developments (and often it is associated with globalization and its effects), is left out for further research.

Our previous exercise, and similar ones, tries to put tourism development in this more general perspective, as the start and evolution of a multilevel relation between heterogeneous populations which themselves are generally further articulated in mobile communities of interests. The latter notion captures and extends the well known notion of stakeholders. And in fact, our framework captures and simplifies for analytical reason the idea that tourism development is an issue involving various stakeholders. In reality these can be grouped into four: the tourist, the tourist industry (i.e. the set of producers of services for the tourist, in some places big concentrated companies, some places a network of small operators of B\&B and locandas, hosterias etc.), but also the resident (including various territorial administrative bodies), the local cultural heritage.

One important issue is the importance of stability properties of any of the existing equilibria. An unstable equilibrium is surrounded by a region of community distributions which belong to paths leading elsewhere. In less technical jargon, any shock shifting slightly away will initialize a dynamic disequilibrium path. This property, mathematically undesirable as it may be in certain situations, could be used to advantage, if we had a desired distribution that can be made or is naturally stable. In practice, unstable equilibria are rarely observable. In reality, once a long lasting equilibrium has become unstable as a result of an initial structural shock, the community distribution will seek another equilibrium. Directing such a search process is really the objective suited for tourism development policies. Much thought has still to be given to this idea, sifting a fast accumulating experience of bottom up policy designing. 
Emergence of long run bahaviours in a game theoretic setting.../E. ACCINELLL et al.

\section{Bibliography}

BIMONTE S., L. F. and PUNZO, 2006, The evolutionary game between tourist and resident populations and tourist carrying capacity, International Journal of Technology and Globalization.

CASAGRANDI R. and S. RINALDI, 2002, "A theoretical approach to tourism sustainability", in Conservation Ecology, vol. 6 issue 1.

DOWLING, R. K., 1993, "Tourist and resident perceptions of the environment-tourism relationship in the Gascoyne region", Western Australia, in GeoJournal, vol. 29 num. 3

HARRILL, R., 2004, "Residents' attitudes toward tourism development: a literature review with implications for tourism planning", in Journal of Planning Literature, Vol. 18, No. 3

HERNANDEZ, S., J. COHEN, and H. GARCIA, 1996, "Residents' attitudes towards an instant resort enclave", in Annals of Tourism Research, vol. 23, núm. 4.

KATHLEEN L. and Christine A., 2000, "The relationship between residents' attitudes toward tourism and tourism development options", in Journal of Travel Research, vol. 39.

PENNINGTON GRAY, 2005, "Resident attitudes towards tourism in a destination in the stagnation stage of the tourism life cycle", in Sustainable Development and Planning II, vol. 2

PAN, Chih Min, 2006, Research note: A Nash bargaining model for average daily rates. Tourism Economics, vol. 12 num. 3

PUCZKÓ L. and Tamara R., 2000, "Tourist and resident perceptions of the physical impacts of tourism at Lake Balaton, Hungary: issues for sustainable tourism management", in Journal of Sustainable Tourism, vol. 8, num. 6

RAMBONILAZA, M., 2006, "Labelling and differentiation strategy in the recreational housing rental market of rural destinations: the French case", in Tourism Economics, vol. 12 num. 3.

SMITH, V., 1989, Host and guests: the anthropology of tourism, University of Pennsylvania Press, Philadelphia.

WEIBULL, W. J., 1995, Evolutionary game theory, The Mit Press.

ZHANG, J., R. INBAKARAN and M. JACKSON, 2006, "Understanding community attitudes towards tourism and host-guest interaction in the urban-rural border region", in Tourism Geographies, vol. 8, num. 2.

\section{Elvio ACCINELLI}

Doctor en Ciencias por el IMPA. Formación en matemáticas en la Facultad de Ciencias de la Universidad de la República. Profesor visitante de la Universidad Pompeu Fabra, de la Universidad de Siena, de la Universidad Nacional de San Luis y de la Universidad Nacional del Sur, entre otras. Especialidad: economía matemática, en particular, equilibrio general y teoría de juegos. Actualmente es profesor en la Facultad de Economía de la Universidad Autónoma de San Luis Potosí. Miembro del SNI, nivel 2. Posee publicaciones en diferentes revistas 
especializadas.

Correo electrónico: elvio.accinelli@eco.uaslp.mx

\section{Juan Gabriel BRIDA}

Doctor en Economía por la Universidad de Siena y licenciado en Matemática por la Universidad de la República y en educación matemática por el Instituto de Profesores "Artigas". Comenzó su trabajo como profesor en Economía y Matemática para la Facultad de Economía y Administración de la Universidad de Bolzano en octubre del 2004. Antes de emigrar a Italia, fue profesor adjunto, asistente y ayudante de Matemática en la Facultad de Economía de la Universidad de la República. Luego de más de una década de investigación en Economía, su investigación se concentra en dos áreas: la dinámica económica y la economía del turismo.

Correo electrónico: juanGabriel.Brida@unibz.it

\section{Edgar Javier SÁNCHEZ CARRERA}

Maestro en Economía y Economía Política por la Universidad Autónoma Metropolitana y la University of Siena, respectivamente. Es candidato a doctor en economía por la University of Siena. Ha colaborado como asistente de investigación para la Universidad Autonónoma de Coahuila, la Universidad Autónoma Metropolitana, y la Free University of Bozen. Entre sus publicaciones más importantes y recientes destacan: "Preservation of environmental quality and tourist investments", en European Journal of Tourism Research, vol. 1, núm. 1, 2008; "Tourism's impact on long-run Mexican economic growth", en Economics Bulletin, vol. 23, núm. 21, 2008; "A long-run equilibrium demand function: the mexican tourism", Forthcoming in Tourismos: An International Multidisciplinary Journal of Tourism, 2008; "Unicidad del equilibrio de Nash-Cournot bajo correspondencias de mejor respuesta", en Econoquantum Revista de Economía y Negocios, vol. 4, núm. 1, 2008; "Sobre la contracción y concavidad de las funciones de mejor respuesta: unicidad del equilibrio de Nash", en Perspectivas, Revista de Análisis de Economía, Comercio y Negocios Internacionales, vol. 3, nú.. 4, 2008.

Correo electrónico: sanchezcarre@unisi.it

\section{Lionello F. PUNZO}

Catedrático de economía del desarrollo y de economía del turismo sostenible en la Universidad de Siena, UNISI. Dottore in Scienze Economiche, Università degli Studi di Siena; M. Phil. in Economics, London School of Economics. Experto integrante del Tourism Sustainability Group de la DG Empresa de la 
Emergence of long run bahaviours in a game theoretic setting.../E. ACCINELLI et al.

Comisión Europea; Presidente del Osservatorio per il Turismo Sostenibile; Presidente de la licenciatura y maestría en Economía del Medioambiente y del Turismo Sostenible (UNISI); Coordinador del Posgrado y Maestría en Economía y Gestión del Turismo Sostenible, UDELAR y UNISI. Docente e investigador en las áreas del crecimiento y desarrollo, así como del turismo sostenible en Europa, Japón, Estados Unidos de América, Brasil, Colombia, Cuba, México y Uruguay. Consultor Internacional en varios proyectos del Banco Interamericano de Desarrollo y del Programa de las Naciones Unidas para el Desarrollo y de la Unión Europea en América Latina y el área del Mediterráneo; Asesor de la Federación Italiana de Parques para Ecoturismo y de la Cooperación Italiana en el tema de la Economía de los Bienes Culturales y del Turismo.

Correo electrónico: punzo@unisi.it 